\title{
Estágio Curricular nos Cursos de Licenciatura em Química: Concepções, percepção e preparo dos formadores
}

\section{Curricular Teaching Practice in Chemistry Undergraduate Courses: Conceptions, perceptions and education of teacher educators}

DOI: 10.46814/lajdv3n6-009

Recebimento dos originais: 01/10/2021

Aceitação para publicação: 16/11/2021

\author{
Sidilene Aquino de Farias \\ Doutorado \\ Departamento de Química/Instituto de Ciências Exatas/Universidade Federal do Amazonas \\ Av. General Rodrigo Octavio Jordão Ramos, 1200 - Coroado I, Manaus - AM, 69067-005 \\ E-mail: sfarias@ufam.edu.br
}

\section{Luiz Henrique Ferreira}

Doutorado

Departamento de Química/Universidade Federal de São Carlos

Rodovia Washington Luis s/n Km 235 - São Carlos - SP, 13565-905

\section{RESUMO}

O Estágio Curricular consiste em uma dimensão curricular importante e obrigatória nos cursos de formação inicial de professores. Este trabalho teve por objetivo analisar as concepções acerca do Estágio Curricular na formação inicial de professores de Química na Região Norte do Brasil. Para tanto, buscou-se conhecer por meio de entrevista semiestruturada com docentes formadores responsáveis pelo estágio e/ou disciplinas integradoras, bem como a importância que atribuem ao estágio no curso. Os dados obtidos foram organizados de acordo com a técnica a Análise Textual Discursiva. Participaram do estudo 16 docentes formadores de Licenciatura em Química, localizados em cinco dos sete Estados da Região Norte - Acre, Amazonas, Pará, Rondônia e Roraima. Os resultados foram estruturados a partir de duas temáticas perfil profissional e formação docente; concepção sobre o estágio curricular, que mostram que a maioria dos docentes formadores é formada por licenciado e/ou bacharel em Química com Pós-Graduação em uma subárea clássica da Química. Apenas dois docentes formadores mencionaram terem realizados Pós-Graduação na área de Educação Química. Nos relatos dos docentes formadores a principal concepção de estágio configura como momento de aplicar na prática a teoria.

Palavras-Chave: estágio curricular, licenciatura em Química, docentes formadores.

\section{ABSTRACT}

Teaching practice is an important and compulsory curricular dimension in initial teaching courses. This study analyzed the conceptions about Curricular Teaching Practice in Initial Undergraduate Chemistry Courses in the North of Brazil. To this end, the study used semi-structured interviews with teacher educators responsible for teaching practice and / or articulating courses. Another aim was to reveal the importance given to teaching practice in the undergraduate courses. The data was organized according to Discursive Textual Analysis. Sixteen teacher Undergraduate Chemistry Courses from five of the seven states of the North of Brazil participated of the study - Acre, Amazonas, Pará, Rondônia and Roraima. The results were organized into two categories: professional profile and teacher education 
and, conception about teaching practice demonstrate that most teacher educators have a teaching and/or baccalaureate in Chemistry and postgraduate studies in some classical subarea of Chemistry. Only two teacher educators had a postgraduate degree in Chemistry Education. Teacher educators' reports pointed out that teaching practice is understood as the space and locus to put theory into practice.

Keywords: curricular teaching practice, Chemistry teaching degree, teacher educators.

\section{INTRODUÇÃO}

Para uma formação integral que contemple saberes formativos, superando a dicotomia entre teoria e prática, e que responda as demandas sociais atuais exigidas para a Educação Básica, a concepção de estágio na formação de professores objetiva explicitar aspectos metodológicos, epistemológicos e atitudinais na construção de conhecimentos de conteúdo específico, pedagógicos e integradores.

O Estágio Curricular (EC) supervisionado de ensino se apresenta consiste em um componente curricular, obrigatório no Projeto Pedagógica do Curso (PPC), cuja finalidade é integrar conhecimento, consolidando e articulando "[...] competências desenvolvidas ao longo do curso, por meio das demais atividades formativas, de caráter teórico ou prático” (BRASIL, 2005, p. 3).

Atualmente, as Diretrizes Curriculares Nacionais para a Formação Inicial de Professores para a Educação Básica e institui a Base Nacional Comum para a Formação Inicial de Professores da Educação Básica (BNC-Formação), instituídas pela Resolução CNE/CP N 2/2019, destaca que no artigo $7^{\circ}$, inciso VIII, que o Estágio Curricular configura como um espaço de prática com foco no planejamento, na regência e na avaliação de aula, sob orientação de professores ou supervisores experientes da escola campo do estágio (BRASIL, 2019).

Nesse sentido, enfatiza-se que este texto tem por objetivo conhecer o perfil profissional dos docentes formadores que atuam nos Estágios Curriculares dos cursos de formação inicial de professores de Química na Região Norte do país. E ainda, conhecer as concepções desses docentes formadores que subjazem suas práticas educativas na formação dos futuros professores de Química.

\subsection{DIFERENTES CONCEPÇÕES SOBRE OS ESTÁGIOS NA FORMAÇÃO DE PROFESSORES}

De acordo com Pimenta e Lima (2008), o estágio era entendido como parte prática dos cursos de formação profissional. Nessa perspectiva, o estágio configurava como imitação de modelos, onde o modo de aprender a profissão se dava a partir da observação, imitação, reprodução e, às vezes, reelaboração dos modelos existentes, sendo esta compreensão uma característica do modo tradicional de atuação docente. Outra configuração clássica dos estágios é a compreensão da prática como instrumentalização técnica. As autoras enfatizam que as atividades de estágio ficam reduzidas a hora 
da prática, ao como fazer, sendo o mais importante o treinamento de habilidades profissionais com enfoque no emprego de métodos e técnicas.

Na superação dos enfoques apresentados acima, faz-se necessário compreender que o estágio é teoria e prática. A teoria contribui na análise e investigação que auxiliam no questionamento de práticas institucionalizadas e as ações dos sujeitos e ao mesmo tempo coloca-a, também, em questionamento, pois as teorias são explicações sempre provisórias da realidade. Cumpre enfatizar que a teoria se relaciona com a prática educativa, que consiste em formas de educar em diferentes contextos nos âmbitos da sociedade e de suas instituições. Dessa forma, o estágio na formação de professores visa "[...] possibilitar que os futuros professores compreendam a complexidade das práticas institucionais como alternativa no preparo da inserção profissional.” (PIMENTA; LIMA, 2008, p. 43).

Nessa perspectiva, buscando superar concepções tradicionais de compreensão do estágio que dicotomizam teoria e prática, o estágio necessita ser compreendido como uma aproximação da realidade e, ao mesmo tempo, uma atividade teórica por meio apropriação da realidade, para analisála, questioná-la a luz das teorias, objetivando a transformação da realidade. Outra proposta de superação é vivenciar o estágio como pesquisa e a pesquisa no estágio. Este segundo enfoque possibilita os estagiários desenvolverem postura e habilidades em suas vivências na escola, elaborando projetos que permitam compreender e problematizar as situações que observam (PIMENTA; LIMA, 2008).

Dialogando com modelos de formação de professores e buscando compreensões acerca da importância formativa do Estágio Curricular em cada modelo, Paquay e Wagner (2001) analisaram as práticas de formação através dos estágios. Para tanto os autores apresentam seis modelos formativos de professores, enfatizando as principais características do estágio: professor culto; técnico; prático

\section{artesão; prático reflexivo; ator social; pessoa.}

Os três primeiros modelos de formação de professores acima mencionados são compreendidos como tradicionais, pois privilegiam as competências formativas centradas nos saberes - professor culto; saber-fazer técnico - professor como técnico; esquemas de ação - professor como prático artesão. No modelo de formação de um professor culto, os saberes disciplinares são os mais valorizados, sendo os primeiros a serem vivenciados na formação inicial. Consequentemente, o estágio é vivenciado no final da formação como forma de praticar as teorias apreendidas, considerando principalmente a aplicação de modelos didáticos. Para a formação de um professor como técnico, Paquay e Wagner (2001) mencionam que existe uma lista impressionante de competências específicas a serem desenvolvidas na formação inicial, que conferem aos futuros professores um saber-fazer técnico. No estágio, os autores salientam exercícios progressivos por meio de microensino; lição 
experiência; assim, o futuro professor deverá vivenciar no final da formação o desenvolvimento de diversas técnicas apreendidas no decorrer do curso.

Em relação ao terceiro modelo tradicional de formação de professores, apresentado por Paquay e Wagner (2001), professor como prático artesão - a formação inicial desloca para outro extremo, passando a ter centralidade na prática, compreendendo o estágio como espaço em que os estudantes adquirem e automatizam os esquemas de análise e de ação necessários para organizar a classe e dirigir os aprendizados. Contudo, sem o devido cuidado de analisar criticamente os saberes práticos, desconsiderando o diálogo entre teoria e prática, o estágio nesse modelo de formação pode contribuir como espaço de reprodução das práticas dominantes.

[...] os estágios também são, com frequência, a oportunidade para o futuro professor se moldar ás praticas tradicionais, descobrir e reforçar as receitas que tem em vista o aluno médio, em suma, de adquirir um "saber prático" inteiramente separado da teoria. Parece mesmo que os estudantes mais inseguros apegam-se a esses "saberes práticos" a ponto de se tornarem herméticos a qualquer reflexão teorizante [...] (PAQUAY; WAGNER, 2001, p. 139).

Em contraste com as três concepções acima apresentadas, o professor como prático reflexivo consiste num profissional autônomo que apresenta, entre outras características, saber orientar seu próprio aprendizado através de uma análise crítica de suas práticas e dos resultados destas. Na formação inicial orientada para preparar um professor prático reflexivo diversas estratégias podem ser utilizadas, como vivenciar análise de situações-problema no estágio e a construção de um diário reflexivo. Paquay e Wagner (2001) mencionam que o desenvolvimento de pesquisa é importante como atividade no estágio, visto que privilegiam a formação de práticos eficazes e em reflexão. Contudo, destacam que a centralidade das atividades de estágio deve pautar se na organização do acompanhamento pelos professores, considerando que eles próprios estejam habituados a refletir sobre suas práticas.

$\mathrm{Na}$ formação do professor como um prático reflexivo Perrenoud et al. (2001) destaca cinco competências que devem ser consideradas nos estágios:

a) Aprender a ver e analisar - conhecer as estratégias do professor especialista e a rotina de uma sala de aula;

b) Aprender a ler, ouvir e explicar - ou seja, interpretar a observação da realidade, confrontar seus distintos elementos constitutivos e explicitar suas próprias reflexões;

c) Aprender a fazer - adquirir os saberes práticos, com a experimentação das estratégias aprendidas teoricamente, mas com o respaldo de profissionais experientes para lidar com as angústias e inseguranças do licenciando;

d) Aprender a refletir - tornar a reflexão sobre a prática um hábito, não apenas após a prática, mas que aconteça naturalmente no momento da ação; 
e) Transpor para a formação profissional - transformar os saberes eruditos e técnicos, tornandoos acessíveis ao aprendiz.

Em suma, é preciso que o estagiário seja preparado para que saiba observar, registrar suas observações e, além disso, que saiba compará-las e conservá-las.

Finalizando a abordagem sobre os modelos de formação de professores, Paquay e Wagner (2001) destacam as concepções de formação de professores pautadas nas dimensões sociais e psicológicas: professor como ator social e professor como pessoa, respectivamente. A primeira concepção implica no envolvimento do professor em nível local, participando de projetos coletivos, participação na gestão escolar, analisando os problemas sociais que invadem a escola e tomar consciência dos desafios sociais. Nesse sentido, o estágio é um espaço privilegiado, pois possibilita o estudo de situações conflituosas que proporcionam a integração entre teoria e prática. No tange a dimensão psicológica, os autores destacam o modelo de formação do professor como pessoa, considerando que a formação inicial necessita contemplar o desenvolvimento pessoal e relacional. Com esse entendimento, o estágio é um espaço insubstituível para desenvolver atitudes, posturas, relações afetivas na prática educativa, construir uma identidade profissional.

\subsection{O PAPEL DO DOCENTE UNIVERSITÁRIO NA FORMAÇÃO DE PROFESSORES}

No que tange ao desenvolvimento das concepções supramencionadas nos cursos de formação inicial, é imprescindível que os docentes formadores responsáveis pelas disciplinas que compõem o Estágio Curricular orientem as atividades de maneira a contemplar as diversas competências profissionais. Isto porque estas competências têm como lócus privilegiados nos espaços formais de educação, e ainda, podem ser complementadas com vivências educativas em espaços não formais.

Nessa perspectiva, Razuck e Razuck (2021), ao estudarem a concepção de licenciandos, em Ciências Naturais acerca da abordagem CTS, apontam que os formadores no Estágio Curricular podem contribuir de maneira significativa contribuir na formação de futuros professores, por meio do desenvolvimento de atividades que propiciem a integração integrar pesquisa e extensão, e promovam a intervenção sobre a realidade e a produção de conhecimento.

Nessa perspectiva, é importante considerar as concepções de formação de professores, de educação, de homem, de mundo, de ensino e aprendizagem, entre outras que subjazem as ações da instituição formadora. A formação do professor universitário, em relação ao seu preparo pedagógico não configura como exigência para adentrar no magistério superior. A esse respeito, Balzan (1996 apud Gonçalves e Gonçalves, 1998) salienta que o professor universitário é o único profissional de nível 
superior que entra para uma carreira sem que passe por qualquer julgamento acerca dos pré-requisitos - competência e experiência prévia - no domínio das habilidades de sua profissão.

Zabalza (2004) aponta que existem duas concepções a respeito dos saberes dos professores universitários. Uma delas parte da premissa de que o que define o papel formador dos docentes universitários e a sua dimensão profissional essencial não são as disciplinas específicas que lecionam, mas o papel formador que deles é exigido. A outra concepção defende uma orientação mais disciplinar, baseando-se no entendimento de que os processos de ensino/aprendizagem estão condicionados pelos conteúdos próprios de cada disciplina. Para o autor, todos os professores têm em comum a função docente e seus conteúdos, denominam-se espaço compartilhado no qual podem ocorrer trocas de experiências e conhecimentos.

Nessa mesma linha de pensamento, Dinham (1996 apud PACHANE, 2003) enfatiza que para ensinar efetivamente, os professores necessitam não apenas da substância de sua área de atuação - no caso dos professores formadores de Química, o conhecimento químico - mas também de suas bases paradigmáticas, suas estruturas sintáticas, suas próprias crenças - todos estes aspectos merecem sua atenção e reflexão; é necessário que o professor reflita sobre as bases epistemológicas acerca da área do conhecimento que ensina, o que acreditam sobre a educação em sua área, e como estas crenças influenciam seu ensino, entre outros aspectos.

\section{DESENHO METODOLÓGICO}

Apresentamos os resultados de um estudo realizado em doze cursos de Licenciatura em Química presenciais pertencentes à Instituições de Educação Superior (IES) públicas, localizadas na Região Norte do país, em cinco dos sete Estados da Região Norte - Acre, Amazonas, Pará, Rondônia e Roraima.

A coleta de dados nas IES foi realizada in loco, tomando-se como critério de participação dos possíveis sujeitos da pesquisa, docentes que fossem responsáveis pelas disciplinas de Estágio Supervisionado e disciplinas integradoras - pertencentes à Prática como Componente Curricular -, conforme o trabalho desenvolvido por Kasseboehmer (2006). Além desses sujeitos, outros docentes que ministravam disciplinas de conhecimento específico, manifestaram interesse em participar da pesquisa. Sendo assim, participaram um total de 16 docentes diretamente vinculados aos cursos. $\mathrm{Na}$ apresentação dos dados na discussão dos resultados, os nomes dos entrevistados foram resguardados, assim como não é feita discriminação de gênero. Assim, adotou-se identificar o docente formador por "DF".

Para o desenvolvimento deste trabalho adotou-se a entrevista semiestruturada, uma vez que este tipo de instrumento permite ao entrevistado discorrer e verbalizar seus pensamentos, tendências e 
reflexões sobre os temas apresentados. De acordo com Alves-Mazzotti e Gewandsnajder (2004) a entrevista, por sua natureza interativa, permite tratar de temas complexos que dificilmente poderiam ser investigados adequadamente por meio de questionários, explorando-os em profundidade. Sendo assim, privilegia a fala dos atores sociais e, com isso, permite atingir um nível de compreensão da realidade que se torna acessível por meio de discursos, sendo apropriada para investigações cujo objetivo é conhecer como as pessoas percebem o mundo (FRASER; GONDIM, 2004).

Nesse sentido, buscou-se conhecer as concepções, vivências e percepções dos formadores acerca do estágio curricular e a contribuição desse componente curricular obrigatório na formação inicial de professores de Química, a partir da visão do docente formador. Para tanto, foram apresentados questionamentos para os docentes formadores (Quadro 1).

Quadro 1. Questões apresentadas no roteiro da entrevista semiestruturada para os docentes formadores participantes a pesquisa.

\begin{tabular}{|l|l|}
\hline Participantes da Pesquisa & \multicolumn{1}{|c|}{ Roteiro da Entrevista Semiestruturada } \\
\hline \multirow{3}{*}{ Docente Formador (DF) } & 1. Você fez bacharelado e/ou licenciatura? \\
& 2. Comente sobre sua formação docente e opção pelo magistério. \\
& 3. Qual a importância do Estágio Supervisionado para o Curso de \\
& Licenciatura em Química? \\
\hline
\end{tabular}

Fonte: elaborado pelos autores.

Para analisar os questionamentos acima, utilizou-se os pressupostos teórico-metodológico da Análise Textual Discursiva (ATD) (MORAES; GALIAZZI, 2007). A ATD proporciona uma interpretação aprofundada mediante um processo auto-organizado de construção de novos significados relacionados ao objeto de estudo, a partir de materiais textuais referentes a esses fenômenos. Destacase que a ATD se inicia com a fragmentação dos textos para produzir as unidades de análise, sendo essa etapa denominada de unitarização, o pesquisador irá fragmentar os textos e codificar cada unidade. Em seguida, irá reescrever essas unidades de modo a assumir um significado, o mais completo possível em si mesmo. Por fim, o pesquisador atribuirá um nome ou título para cada unidade produzida. Diante disso, a partir dos dados obtidos foram elaboradas duas temáticas de análise: perfil profissional e formação docente; concepção sobre o estágio curricular.

\section{RESULTADOS E DISCUSSÃO}

Conforme mencionado anteriormente, participaram dezesseis docentes que atuam em doze cursos de Licenciatura em Química de IES públicas, localizados na Região Norte do Brasil. Na tentativa de compreender como o Estágio Curricular está contribuindo para a formação de futuros professores de Química, para além das normativas legais, buscou-se conhecer o perfil profissional dos 
docentes formadores, a formação docente e opção pelo magistério. A partir da análise das respostas foram propostas as temáticas perfil e formação profissional, e concepções sobre o estágio curricular.

\subsection{PERFIL PROFISSIONAL E FORMAÇÃO DOCENTE}

Referente a formação inicial dos DF - formação na graduação - foi possível observar que aproximadamente $62 \%$ dos participantes da pesquisa são licenciados em Química, sendo que dentre estes apenas 5 participantes também são bacharéis e 2 químicos industriais. E ainda, conforme pode ser observado na Tabela 1, 19\% dos DFs

são somente bacharéis e 19\% realizaram outros cursos - Engenharia Química, Química Industrial e Pedagogia.

Em relação ao docente formado em Pedagogia, o curso D tem organização diferente dos demais cursos, pois o estágio consiste em atividade a ser realizada, mas não configura na matriz curricular do curso como disciplina. Nesse sentido, o DF6 atua como coordenador das atividades relacionadas ao Estágio e os docentes formadores, com formação específica em Química, orientam os licenciandos no estágio (FARIAS; FERREIRA, 2011).

Em relação à formação na pós-graduação, observou-se que apenas dois docentes formadores (13\%) realizaram estudos em nível de pós-graduação com ênfase na área de pesquisa Ensino de Química. Esse é um fator importante, visto que sua formação e atuação como pesquisador valorizam conhecimentos necessários a compreensão de uma formação numa perspectiva crítica sobre a escola, as desigualdades sociais, as atividades cotidianas na sala de aula e na escola, contribuindo dessa forma significativamente na construção da identidade docente no desenvolvimento do Estágio Curricular (SACRISTÁN; GÓMEZ, 2000). Nesse sentido, o relato do DF1 contribui nesse entendimento:

[...] pesaram muito na formação docente foi a opção pelo mestrado em Educação, depois de ter feito o primeiro mestrado, porque aí possibilitou, é... como o pessoal diz, né, na Educação, te molhar de várias teorias e também o tempo que eu trabalhei na ONG que era com cursinho popular também ajudou muito, porque era um grupo de professores muito focado, com uma formação humana muito boa, então isso ajudou muito na minha formação docente (Curso A, DF1).

Outro aspecto importante presente na fala do docente formador são as experiências vivenciadas no âmbito da docência. Cumpre destacar que tais experiências necessitam ir além do ensino do conteúdo específico, visando assumir um compromisso ético e profissional, e ainda, superar as limitações de modelos de formação de professores tradicionais. Concordamos com Paquay e Wagner (2001) que é importante o professor analisar problemas sociais que invadem a escola e tomar consciência dos desafios sociais. Nesse sentido, também são importantes que os formadores possam mostrar e orientar os estagiários em práticas que envolvam a interação entre Ciência, Tecnologia e 
Sociedade no tratamento do conhecimento específico e, com isso propiciem atividades que contemplem relações entre ensino, pesquisa e extensão (RAZUCK; RAZUCK, 2021).

Tabela 1. Perfil profissional dos docentes formadores nos cursos de LQ na Região Norte do país.

\begin{tabular}{c|l|c}
\hline \hline Nível & \multicolumn{1}{|c|}{ Curso } & $\mathbf{1}$ \\
\hline \hline \multirow{4}{*}{ Graduação } & Licenciatura em Química & 19 \\
\cline { 2 - 3 } & Bacharelado em Química & 19 \\
\cline { 2 - 3 } & Licenciatura e Bacharelado em Química & 31 \\
\cline { 2 - 3 } & Licenciatura em Química e Química Industrial & 12 \\
\cline { 2 - 3 } & Outros cursos & 19 \\
\hline \multirow{3}{*}{ Pós-Graduação } & Mestrado e/ou Doutorado em Educação/Ensino de Química & 13 \\
\cline { 2 - 3 } & Doutorado em subáreas clássicas da Química & 56 \\
\cline { 2 - 3 } & Outros & 31 \\
\hline
\end{tabular}

Fonte: elaborado pelos autores.

Portanto, o docente formador, responsável na orientação das atividades de estágio, precisa ter leituras e experiências que proporcionem um olhar mais apurado acerca da prática educativa nas escolas que proporcionem uma formação política, que considere o ensino um ato social e emocional, entendendo que o processo de ensino/aprendizagem bem-sucedido acontece quando eles são responsáveis e solidários com a aprendizagem dos seus alunos (HARGREAVES, 2004).

Outra experiência que contribui de maneira significativa proporcionando a reflexão acerca do processo de aprender e ensinar, bem como de posturas éticas, consiste nas orientações em programas de pós-graduação em Ensino de Ciências/Química. Vale ressaltar que pesquisas no âmbito do ensino de áreas específicas, nas ciências Exatas como a Química, são recentes no Brasil. Além disso, a formação de pesquisadores nesse âmbito não ocorreu de maneira homogênea no território nacional, havendo maior concentração de pesquisadores dessas áreas nas regiões Sudeste e Sul. Nessa perspectiva, o docente formador do curso G menciona ter atuado num programa de pós-graduação em ensino:

Depois eu fiz a minha pós-graduação na área de Química Inorgânica, mestrado e o doutorado na área de Físico-Química. Na verdade, apesar disso, eu trabalhei na pós-graduação tanto na Química quanto na área de Ensino, de Educação, [...] nós temos o Instituto de Ciências, e é ensino de Ciências e Matemática, [...]. (Curso G, DF10).

O docente formador do relato acima contribuiu para o percentual de docentes com formação em nível de pós-graduação em subáreas clássicas da Química (56\%) presentes na Tabela 1. Por fim, em relação a outros programas de pós-graduação foram mencionados por $36 \%$ dos participantes, especialização em Coordenação Pedagógica, Doutorado em Biotecnologia e Doutorado em Geociências. 
Retomando as vivências e experiências, vários docentes informaram terem iniciado sua trajetória docente nas escolas da Educação Básica. Entende-se que essas vivências podem contribuir de maneira significativa com o desenvolvimento das atividades do Estágio Curricular. Por outro lado, faz-se necessário que essas vivências sejam analisadas criticamente e proporcionem a reflexão acerca de práticas tradicionais, na perspectiva de superar visões simplistas como, por exemplo, para ensinar basta ter o domínio do conteúdo. Com isso, evita-se transformar os estágios em espaço de reprodução das práticas dominantes.

Assim, foi possível observar nos relatos dos docentes formadores que estes foram professores em escolas da Educação Básica no início de suas trajetórias.

Trabalhei numa escola lá no (...) né, a (...) que foi a primeira escola que eu entrei (Curso C, DF3).

Na realidade, na realidade, eu entrei no Estado... eu entrei no Estado primeiro lá no (...), depois no (...), que são escolas estaduais e no outro ano eu entrei aqui no instituto, [...] (Curso E, DF7).

Eu comecei com Educação Ambiental e Ciências, depois que eu fui passar pro Ensino Médio pra dar aula pro Ensino Médio mesmo (Curso C, DF4).

O DF4, em outro momento de sua fala menciona que o fato de assumir disciplinas do Estágio Curricular tem relação com a sua experiência anterior nas escolas de Educação Básica. Acredita que por ter vivenciado o referido nível de ensino lhe foi creditada a responsabilidade de direcionar a formação dos licenciandos nas escolas, pois sua formação na pós-graduação ocorreu em uma subárea clássica da Química. Por outro lado, o DF12 entende que ter lecionado no Ensino Médio, antes de concluir o Bacharelado em Química, não contribuiu para a sua formação docente.

[...] eu entrei como professor de carreira na federal e comecei trabalhando no interior, né, que fui contratado pra uma experiência que a (...) tava tendo de expansão; então fui contratado pra trabalhar em (...). Então, foi aí que eu adquiri minha experiência mais do magistério, embora tenha trabalhado como professor do Ensino Médio, né, na minha graduação, por pouco tempo (Curso I, DF12).

Diante desse relato é possível inferir que a formação pedagógica poderia contribuir para superar visões simplistas acerca da profissão docente. Entende-se ser necessário que o professor reflita sobre o que seus colegas pensam sobre educação em suas áreas e como estas crenças influenciam seu ensino, entre outros aspectos; estas são vivências que podem contribuir para um olhar analítico acerca da prática educativa na sala de aula e no contexto escolar (DINHAM 1996 apud PACHANE, 2003).

Outro relato interessante e que caracteriza muitos professores no início da carreira é percepção acerca da própria profissão que se traduz em desvalorização da docência. A esse respeito, o ingresso na docência ocorreu por uma necessidade e não por uma decisão pessoal, uma convicção acerca da 
profissão escolhida. O DF13, do Curso J possui formação na pós-graduação, também, em subárea clássica da Química.

Na verdade, a opção pela docência ocorre muitas vezes por falta de oportunidade em outros setores econômicos que necessitam do conhecimento químico.

[...] diante da necessidade de professor na região né, e aí que o pessoal... eu acabei enveredando pra esse lado, por o pessoal falar que precisava de professor, me chamavam e eu fui (Curso J, DF13).

[...] foi a primeira vez que foi na Escola Técnica. Eu atuei já pensando na Escola Técnica, pensando num trabalho pra indústria. [...] (Curso K, DF14).

Por outro lado, também foi possível observar relatos de docentes formadores que mesmo tendo escolhido a licenciatura no início da carreira por ser o curso disponível, no seu primeiro contato com a escola, identificou-se com a profissão docente, entendendo que o professor necessita de domínio profundo do conhecimento a ser ensinado, bem como estar sempre estudando.

[...] E nessa história, eu fui informado que estavam procurando professor de Química para o Ensino Médio no colégio. Na época era contratado, aí eu me apresentei à noite, não tinha outro compromisso que impedia fazer. Aí eu comecei no Ensino Médio a dar aula à noite. Mas isso, vamos dizer que foi algo que pra mim me despertou dado a dificuldade que os alunos tinham, e também como eu nem sabia tanto da Química quanto eu achava que eu sabia, mas devia saber perante os alunos. Sabe, houve então uma revolução até comigo nesse ponto. Eu digo poxa na verdade não sei nada de Química. Eu vim pra cá achando que eu era um químico, mas não sou tanto, um pouco limitado. E aí então o estudo dentro desse emprego [área técnica] não é uma exigência tão grande quanto no ensino, que necessita você estudar continuamente pra você estar lecionando (Curso L, DF15).

Finalizando, uma vivência importante relatada por dois docentes formadores que possivelmente contribuiu de maneira significativa na opção pela carreira docente foi a participação em espaços não formais de educação, relacionados aos movimentos sociais. Conforme apresentado no primeiro relato desta secção, foi um dos motivos do DF1 optar pela docência, contribuindo na formação humana com compromisso social e ético. Da mesma forma, pode ser observado no relato do DF9, destacando que não tinha intenção de se tornar professor, já que sua formação se deu no curso de Graduação de Química Industrial.

Não, não quero ser professor. [...], alguém me convidou pra dar aula naquele... Não sei se você chegou a ouvir falar do MOBRAL, né. Eu não dei aula no MOBRAL, mas eu me tornei monitor do Movimento de Educação de Base. Que era chamado MEB, que era da igreja católica, da CNBB com a Arquidiocese, [...]. Aí eu disse, mas eu não tenho experiência - Não, você vai fazer um curso de preparação. - Aí eu fiz na Diretoria de Educação lá de [nome da cidade] que era a responsável pela difusão naquela região. Eu fiz esse curso e fiquei empolgado. Gostei muito. Aí depois fui enfrentar uma turma (Curso G, DF9). 


\subsection{CONCEPÇÃO SOBRE O ESTÁGIO CURRICULAR}

Buscando conhecer as concepções, crenças e valores que direcionam as atividades relacionadas ao Estágio Curricular e como esse componente contribui na formação inicial de professores de Química na Região Norte do país, perguntou-se aos docentes formadores “Qual a importância do Estágio Supervisionado para o Curso de Licenciatura em Química?". Nos doze cursos de Licenciatura em Química participantes deste estudo o estágio ocorre, preferencialmente, em escolas públicas. Em oito cursos as principais atividades são: observação, planejamento de ensino e avaliação, regência (execução de aulas teóricas e práticas). Conforme pode ser verificado no trecho abaixo do relato do DF8 do Curso F:

Então, mostra agora o seguinte, primeiro ele observa, ele se prepara e tal; no segundo ele tá na regência; no terceiro ele vai fazer alguma coisa de intervenção. Então essa... quando chega na intervenção, de repente de propor metodologias, de rever o que está sendo feito no laboratório, de criar uma feira de ciências. Então, esse é o nosso diferencial de Estágio.

A partir dos resultados obtidos foi possível constatar que alguns docentes formadores apresentam suas concepções acerca do Estágio limitando-se em apresentar compreensões sobre a organização do Estágio Curricular presente na matriz curricular do curso e no Projeto Pedagógico do Curso (PPC). Sendo assim, pode-se verificar nos relatos duas compreensões: o estágio como disciplina e como atividade. O estágio como atividade está presente no Curso D, como pode ser observado fala da DF6:

$\mathrm{Na}$ verdade, não tem disciplina. Ele vem aqui, a partir do sexto período em diante, né, desculpe, do quinto período em diante, ele já pode se matricular [...].

No Curso A, o EC se confunde com disciplinas da Prática como Componente Curricular (PCC), denominada Prática de Ensino, conforme relata o DF1, configurando também como atividade presente na disciplina Prática de Ensino:

Olha, no nosso curso, especificamente, a importância dela [Prática de Ensino] é que o estágio é contemplado basicamente por ela, mas isso é ao mesmo tempo um problema né. Porque eu vejo que o estágio deveria ser uma disciplina a parte, o Estágio Supervisionado como disciplina.

Por outro lado, a concepção criticada pelo DF1 do Curso A, o DF4 do Curso C entende como sendo atual, pois informa que na organização do curso em que atua, o Estágio é denominado Prática de Ensino: 
Hoje, o estágio é chamado de prática. O estágio é chamado de Prática de Ensino de Química e Ciências (Curso C, DF4).

Todavia, o docente formador do Curso A entende que o Estágio deveria ocorrer separadamente das disciplinas que compõe PCC e atribui importância quando menciona que o Estágio não pode reduzir-se ao final do curso, ou seja, é preciso superar modelos clássicos de formação de professores (PAQUAY; WAGNER, 2001). Nesse entendimento, o docente formador expressa seus valores, crenças e compreensões que vão além dos documentos oficiais do curso, e que possivelmente, for $\mathrm{m}$ construídos no decorrer de sua trajetória docente num constante diálogo entre as teorias educacionais e a prática educativa.

Nessa mesma perspectiva, o DF10 do Curso G, entende que o Estágio é importante para a formação do licenciando e que a formação necessita permear todo o curso, desde o início. Contudo, apresenta entendimentos de que o estágio é o momento para colocar em prática as teorias que aprendidas.

Eu acho, é a minha opinião, de que essa formação pedagógica para o licenciado não tem que acontecer no último semestre do curso, ela deve acontecer desde o primeiro semestre do curso. Você tá formando o licenciado. Tá certo? Então é de fundamental importância pra que eles tomem contato com o exercício da profissão, pra que eles possam colocar em prática a teoria que eles aprenderam na universidade (Curso G, DF10).

Esse entendimento sobre o estágio ser o momento de aplicar as teorias aprendidas no curso também está presente na fala de outros docentes formadores, como pode ser observado nos relatos abaixo:

O Estágio... quando o nosso aluno está próximo do Estágio, entre aspas, né, ele já passou um pouquinho, de formação na parte específica dele no curso. Ele já teve alguns componentes da parte pedagógica e é o momento de você encarar a vida futura (Curso $F, D F 8$ ).

[...] por isso a importância dessa disciplina, porque a gente tenta amenizar muito isso. Do aluno verificar tanto na teoria como atuar na prática (Curso H, DF11).

Esse... esse que eu digo, como a inserção mesmo dele no mercado, na prática, né (Curso I, DF 12).

O estágio, ele tem... Como professor é uma prática né, seria já do assunto do pré-profissional né. Essa situação, como em todas as áreas têm, porque já é uma... já é o momento que ele se ajusta como profissional, pra ir pro mercado né. Aí tem dois parâmetros né, que seriam né, no caso se ele for um licenciado, a parte de assessoria, de questões de projeto e tal, e da prática de ensino né (Curso K, DF13).

No Estágio Supervisionado é onde você avalia diretamente o teu aluno no todo. Ele já teve toda a sua formação e agora ele vai pra regência. Então, é aí que você avaliar se o seu aluno sabe transmitir e aí é a hora de corrigir qualquer defeito (Curso B, DF2). 
A compreensão sobre o estágio apresentada nos relatos acima vai ao encontro das configurações clássicas dos estágios apresentadas por Pimenta e Lima (2008). Nesse sentido, é importante que o docente formador tenha conhecimento sobre os modelos de formação de professores e os objetivos do estágio em cada modelo (PAQUAY; WAGNER, 2001). Nos documentos oficiais orientadores, publicados pelo Ministério da Educação, tais concepções são apontadas como compreensões a serem superadas na formação inicial de professores (BRASIL, 2001).

Finalizando, também foram observadas nos relatos compreensões de que estágio é o momento em que o licenciando irá aproximar-se do contexto real em que irá desenvolver sua atividade profissional, e ainda, como espaço para desenvolver a investigação. Pimenta e Lima (2008) enfatizam que é importante compreender que o estágio é teoria e prática, pois a teoria relaciona-se com a prática educativa. As autoras apontam o estágio como pesquisa e a pesquisa no estágio como forma de superar visões clássicas acerca do estágio. Entretanto, tais entendimentos não ficam claros, pois o docente formador entende que o fato de o licenciando ir para escola observar e que isso indica que está desenvolvendo pesquisa, ainda são concepções ingênuas a que faltam fundamentos teóricos.

Eu acho, assim, que ele vai ter contato real, o mundo real. Que ele tá sendo preparado pra ser professor, ele vai realmente desenvolver aquela atividade em três níveis (Curso F, DF8).

E ele saber trabalhar também a questão da pesquisa, porque muitos TCCs também são voltados pra questão da escola, né. Também aprender a fazer uma pesquisa. Onde ele tem o mínimo de contato aqui na faculdade, eu acho, com relação à pesquisa. Além de ser alunos, né, que ainda não trabalham na escola, de ter aquele contato com a escola. Ir lá observar como é que o professor tá trabalhando [...] (Curso C, DF4).

E pra que também de lá eles tragam algum conhecimento pra dentro da universidade pra somar àquilo que a gente tá aprendendo (Curso G, DF10).

\section{CONSIDERAÇÕES FINAIS}

Sumarizando, para a maioria dos docentes formadores o estágio consiste em momento de colocar em prática as teorias que foram aprendidas no curso, sejam elas teorias químicas como teorias relacionados aos conhecimentos pedagógicos. Esta foi a principal concepção verificada nos relatos dos docentes formadores.

Essas compreensões simplistas sobre o estágio podem ser advindas da formação na graduação. Em relação aos Programas de Pós-Graduação, estes não consideram o preparo de mestres e doutores para atuarem como professores. Nesse sentido, docentes formadores que não realizaram pesquisa científica no campo educacional não tiveram contato com conhecimentos pedagógicos atualizados.

As experiências que os docentes formadores mencionaram em seus relatos - no início da carreira docente - acerca das suas vivências da prática educativa nas escolas de Educação Básica são importantes, mas necessitam ser ressignificadas mediante as teorias educacionais. Portanto, faz-se 
necessário que os docentes formadores busquem qualificação pedagógica para melhorarem o direcionamento das atividades de estágio e/ou que busquem aperfeiçoamento para desenvolver pesquisa na área de Educação Química.

Além disso, é importante que o docente formador das disciplinas de Estágio Supervisionado busque conhecer também a realidade escolar para a qual estão formando os futuros professores de Química, conduzindo as atividades a serem realizadas nas escolas por meio do estabelecimento de parcerias com os professores de Química que atuam na Educação Básica e realizando, ainda, um acompanhamento efetivo das atividades de estágio.

Vale ressaltar ainda que para ampliar tais compreensões e aprofundar o estudo acerca dessas concepções, faz-se necessário buscar conhecer como as atividades do estágio são desenvolvidas tanto na perspectiva do docente formador como de licenciandos formandos.

\section{AGRADECIMENTOS}

Aos Docentes Formadores dos Cursos de Licenciatura em Química das IES públicas da Região Norte do país, pela colaboração na pesquisa.

À FAPEAM, SECT e Governo do Estado do Amazonas, pelo auxílio financeiro. 


\section{REFERÊNCIAS}

ALVES-MAZZOTTI, A. J.; GEWANDSZNAJDER, F. O método nas ciências naturais e sociais: pesquisa quantitativa e qualitativa. $2^{\mathrm{a}}$ ed., São Paulo: Pioneira Thomson Learning, 2004.

BRASIL. Ministério da Educação. Parecer CNE/CP no 009/2001. Diretrizes curriculares nacionais para a formação de professores da educação básica, em nível superior, curso de licenciatura, de graduação plena. Brasília, DF: MEC/CNE, 2001. Disponível em:

<http://portal.mec.gov.br/sesu/arquivos/ pdf/00901formprof.pdf>. Acessado em: 13/11/2021.

BRASIL. Ministério da Educação. Parecer CNE/CES Nº 15, de 2 de fevereiro de 2005. Solicitação de esclarecimento sobre as Resoluções CNE/CP n ${ }^{\circ}$ 1/2002, que institui Diretrizes Curriculares Nacionais para a Formação de Professores da Educação Básica, em nível superior, curso de licenciatura, de graduação plena, e 2/2002, que institui a duração e a carga horária dos cursos de licenciatura, de graduação plena, de Formação de Professores da Educação Básica, em nível superior. Brasília, DF: MEC/CNE, 2005a. Disponível em:

<http://portal.mec.gov.br/sesu/arquivos/pdf/00901 formprof.pdf>. Acessado em: 13/11/2021.

BRASIL. Ministério da Educação. Resolução CNE/CP Nº 2, de 20 de dezembro de 2019.

Define as Diretrizes Curriculares Nacionais para a Formação Inicial de Professores para a Educação Básica e institui a Base Nacional Comum para a Formação Inicial de Professores da Educação Básica (BNC-Formação). Brasília, DF: MEC/CNE, 2005a. Disponível em: <http://portal.mec.gov.br/docman/dezembro-2019-pdf/135951-rcp002-19/file.>. Acessado em: $13 / 11 / 2021$.

FARIAS, S. A.; FERREIRA, L. H. Estágio Curricular: concepções presentes na formação inicial de professores de Química. In: Encontro Nacional de Pesquisa em Educação em Ciências, 2011, Campinas, SP. Atas do Encontro Nacional de Pesquisa em Educação em Ciências, 2011.

FRASER, M. T. D.; GONDIM, S. M. G. Da fala do outro ao texto negociado: discussões sobre a entrevista na pesquisa qualitativa. Paidéia, v. 14, n. 28, 2004, p. 139-152.

GONÇALVES, T. O.; GONÇALVES, T. V. O. Reflexões sobre uma prática docente situada: buscando novas perspectivas para a formação de professores. In: GERALDI, C. M. G.;

FIORENTINI, D.; PEREIRA, E. M. A. (orgs.). Cartografias do trabalho docente: professor(a)pesquisador(a). Campinas, SP: Mercado de Letras: Associação de Leitura do Brasil. 1998. pp. 237274. (Coleção Leituras no Brasil).

HARGREAVES, A. O ensino na sociedade do conhecimento: educação na era da insegurança. Traduzido por Roberto Cataldo Costa. Porto Alegre: Artmed, 2004. 237p.

KASSEBOEHMER, A. C. Formação Inicial de Professores: Uma análise dos cursos de Licenciatura em Química das Universidades Públicas do Estado de São Paulo. 161p. Dissertação de Mestrado em Química. Centro de Ciências Exatas e de Tecnologia, UFSCar, São Carlos, 2006.

PACHANE, G. G. A importância da formação pedagógica para o professor universitário: a experiência da UNICAMP. 268p. Tese de Doutorado em Educação. Faculdade de Educação, UNICAMP, Campinas-SP, 2003. 
PAQUAY, L.; WAGNER, Marie-Cecile. Competências Profissionais Privilegiadas nos Estágio e Videoformação. In: PAQUAY, L. et. al. (orgs.) Formando professores profissionais: Quais estratégias? Quais competências? 2. ed., Porto Alegre: Artmed, 2001, p.211-223.

PERRENOUD, P.; ALTET, M.; CHARLIER, E.; PAQUAY, L. Fecundas incertezas ou como formar professores antes de ter todas as respostas. In: PAQUAY, L. et. al. (orgs.) Formando professores profissionais: Quais estratégias? Quais competências? 2. ed., Porto Alegre: Artmed, 2001, p.211223.

PIMENTA, S. G.; LIMA, M. S. L. Estágio e Docência. 3. ed., São Paulo: Cortez, 2008.

RAZUCK, R. C. S. R.; RAZUCK, F. B. Análise do Enfoque CTS no Estágio Supervisionado de um curso de Licenciatura em Ciências Naturais. Latin American Journal of Development, Curitiba, v.3, n. 3, p. 1379-1388, mai./jun.2021.

SACRISTÁN, J. G. e GÓMEZ, A. I. P. Compreender e transformar o ensino. 4. ed. Porto Alegre: Artmed, 2000.

ZABALZA, M. A. O ensino universitário: seu cenário e seus protagonistas. Porto Alegre: Artmed, 2004. 239p. 